\title{
Management Challenges and Opportunities for Energy Cloud Development and Diffusion
}

\author{
Jones Luís Schaefer ${ }^{1, * \mathbb{C}}$, Julio Cezar Mairesse Siluk ${ }^{1}$, Patrícia Stefan de Carvalho ${ }^{1}$, \\ José Renes Pinheiro 2,3@ and Paulo Smith Schneider ${ }^{4}$ \\ 1 Department of Production and Systems, Federal University of Santa Maria (UFSM), Santa Maria, \\ Rio Grande do Sul 97105-900, Brazil; jsiluk@ufsm.br (J.C.M.S.); patricia_stefanc@hotmail.com (P.S.d.C.) \\ 2 Department of Processing in Electrical Energy, Federal University of Santa Maria (UFSM), Santa Maria, \\ Rio Grande do Sul 97105-900, Brazil; jrenes@gepoc.ufsm.br \\ 3 Department of Electrical Engineering and Computing, Federal University of Bahia (UFBA), Salvador, \\ Bahia 40210-630, Brazil \\ 4 Department of Mechanical Engineering, Federal University of Rio Grande do Sul, Porto Alegre, \\ Rio Grande do Sul 90040-060, Brazil; pss@mecanica.ufrgs.br \\ * Correspondence: engjlschaefer@yahoo.com.br; Tel.: +55-51-997-119-612
}

Received: 26 June 2020; Accepted: 3 August 2020; Published: 5 August 2020

\begin{abstract}
The use of emerging technologies such as cloud computing, Internet of Things, and Big Data, is increasing as tools to assist the management of data and information related to energy systems grow. This allows for greater flexibility, scalability of solutions, optimization of energy use, and management of energy devices. In this sense, the objective of this research is to present the basic elements and requirements for the energy cloud and its management and discuss the main management challenges and opportunities for the development and diffusion of the energy cloud. This study was based on a systematic review carried out to identify the elements that compose the energy cloud and what is necessary for its management, and to list the challenges and opportunities that may be explored by researchers and practitioners. The results show that the layout for the energy cloud and its management can be structured in layers and management support blocks' format. It was found that 70 basic elements make up the main layers and 36 basic elements make up the management support blocks. The findings of this article also provide insights into the technical, scientific, and management development necessary for the evolution of energy systems toward the cloud computing environment.
\end{abstract}

Keywords: energy cloud; energy management; energy cloud management; cloud computing; Internet of Things

\section{Highlights:}

- Shows a layout with the basic structures and management requirements of energy cloud

- Presents the elements and activities for this energy cloud management layout

- Discusses challenges and opportunities for energy cloud development and diffusion

- $\quad$ Presents strategies for evolving policies to develop the energy cloud

\section{Introduction}

Electricity is the main energy carrier used worldwide for residential, commercial, and industrial processes, alongside fuels and heat [1]. Due to its growing demand, management measures must be taken to address the shortage of limited resources. In addition, the utility network may not have sufficient capacity to meet demand in the future, and revolutionary changes in these systems 
inspired by the Internet present a greater possibility of control and monitoring in the entire energy system [2]. Therefore, conventional electricity consumers who have small-scale generation facilities become prosumers, that is, they not only consume energy but also generate it in the electricity grid [3]. Such dynamism in power consumption and production affects traditional electricity forecasting and planning models [4], which makes energy management an important and promising tool [5]. Therefore, the concept of the smart grid appears [6].

Technological and infrastructure aspects are the starting points of this innovative process, which aim to ensure a sustainable and reliable energy supply that improves the energy efficiency of cities [7]. The future infrastructure of the power system or smart grid improves the reliability, energy efficiency, safety, flexibility, sustainability, and performance of the current power grid [8]. Thus, technological development in the energy area aims to efficiently control the consumption of energy and resources, increase the insertion of renewable energy sources, and improve the resilience of the electricity grid [9].

With the large-scale integration of renewable energy generation, the distribution of the energy flow in the grid will change, and the energy flow can be reversed [10]. The synergy between various forms of energy represents a great opportunity for improvements in the system [11], as it helps to reduce the emission of carbon particles and greenhouse gases, in addition to reducing energy consumption [2]. From the users' point of view, the cost of energy can be reduced with a certain level of satisfaction. Energy consumption can also be reduced by employing an appropriate strategy that contributes to sustainable development [5]. To help in this process, the energy generation and consumption data can be captured by sensor technologies [12]. Based on the Internet of Things (IoT), these data can be transferred from the physical layer to virtual layers for energy management [12].

In this sense, cloud computing is a technology to remotely store, monitor, and control any data from any place in the world [13]. This technology can be applied successfully in many areas such as the mobile business, electronic commerce, and data storage service [14], which makes revolutionary improvements to the applications of the information technology (IT) industry [15]. Given its flexible and scalable characteristics, being able to handle large volumes of data, cloud computing can also be applied in smart grid domains [2]. Therefore, smart grids are expected to allow utilities to optimally cope with the capacity and load of electricity, which leads to a more environmentally-friendly use of energy in the long run [4]. The following requirements are necessary for supporting smart grid development [16]: energy management, need to support multiple devices in a common platform, information management, layered and heterogeneous architecture, and security and privacy of users. Users need systems capable of managing, analyzing, and transforming large amounts of data into insights relevant to energy management [17]. As an alternative, the energy cloud appears, which fulfills these requirements.

The energy cloud can be considered a platform designed with technical and economic conditions for integrating distributed renewable energy systems with smart technologies like microgrids, smart meters, storage facilities, and IoT technologies [7]. When IoT is integrated with the cloud, real-time service can be provided extensively, and a huge amount of data is produced, which requires a huge amount of storage space that can be provided by the cloud [18]. The management of energy in a cloud platform allows users to easily access the energy management system through public or private clouds via a Web browser or application programming interfaces (APIs) interfaces [19].

In this sense, different layouts and frameworks have been researched to represent the functioning of the energy cloud. Among these, the layout in layers and/or support blocks used to manage the flow of data and information for communication between users and the cloud are highlighted, where each layer or block has a specific function. There is a layer for users to communicate and interconnect with the system as well as the layer for the user and retail market operations for calculating system stability and data storage [3]. Thus, following this approach, each layer has a specific function complementing each other. 
The objective of this article is to present the basic elements and requirements for the energy cloud and its management as well as to discuss the main management challenges and opportunities for development and diffusion of the energy cloud.

This article was motivated by the rapid development of technological aspects related to the acquisition, supervision, monitoring, control, and manipulation of data and information from installations for the generation, distribution, storage, and consumption of electricity, which allows management of these aspects in an interactive and real-time environment. In this sense, there is a need to systematize basic elements and requirements, which relates them and connects them appropriately, pointing out the main points that need special attention so that this technological integration can be achieved to benefit all users of energy systems. Lastly, this article was also motivated by the possibility of giving total autonomy to the users of energy systems concerning the management of distributed generation, purchase, sale, and exchange of energy, storage, and consumption of energy.

It is expected that this article can contribute to the following aspects.

- Presenting the basic elements, activities, and complementary aspects that involve the acquisition, supervision, monitoring, control, and manipulation of data and information related to energy and that travel in a cloud environment;

- Providing a clear view of what is needed from the technical and functional point of view to meet all managerial aspects necessary to make it possible to manage energy in a cloud environment;

- The article also contributes by discussing the main technical and management challenges and opportunities related to the energy cloud, and these discussions may serve as a starting point for researchers to present new technological and managerial developments, which enables the integration of more users to the energy cloud;

- From a business point of view, this article contributes to the presentation and discussion of how to fulfill the fundamental requirements that can enable the integration of the necessary technologies to the energy cloud environment.

The remainder of the article is organized as follows. Section 2 presents a theoretical background. Section 3 details the methodological procedures used. Section 4 presents the basic layout for energy cloud and its management. Section 5 brings a broad discussion about the principal layers of the energy cloud. Section 6 presents a discussion on management support blocks. Section 7 presents policy and legislations discussion, and, lastly, Section 8 shows the conclusions, limitations, and future research.

\section{Theoretical Background}

This section is structured to serve as a theoretical basis on the main themes related to the article, such as energy management, smart grids, IoT, cloud computing, and energy cloud.

\subsection{Energy Management}

Considering the increased demand for energy, suppliers, and consumers are working together to keep this demand at acceptable and safe levels [20]. In addition, to deal with the increase in population, smart city projects have been proposed by many countries and organizations to promote the optimization of energy consumption in cities [21]. In this sense, energy management is essential in micro-grids, homes, and buildings [22] for reliable and efficient energy system operation and control [23]. In traditional power systems, most of the load is uncontrollable and the energy consumption is not easy to measure accurately [24]. Thus, energy management implies the ability to monitor and characterize user usage patterns to design real-time user-centered energy optimization plans [25]. Therefore, new systems and technologies need to be deployed to monitor and control energy data and information, so that new policies can be implemented for energy management [21]. 
Energy efficiency has become necessary in residential and commercial environments, where the reduction of carbon emissions and the price of energy are two of the main factors that lead companies to choose new technologies to reduce their energy consumption [26]. Therefore, an energy management system is essential to control energy production and consumption, and energy efficiency and cost savings in smart homes and buildings depend heavily on the monitoring and controlling methods installed [27]. Thus, these management systems are based on real-time information systems provided by a large number of sensors and actuators interconnected through communication networks [27].

\subsection{Smart Grid}

A smart grid can be described as a transparent, continuous, and instantaneous bidirectional delivery of energy, which allows consumers to have more control over energy decisions [2]. Smart grids combine different energy sources with low carbon technologies, such as renewable energy sources, to minimize costs and environmental impacts, to maximize system reliability, resilience, and stability [28]. This makes the smart grid capable of providing electricity more efficiently and reliably than the traditional grid by operating, communicating, and interacting autonomously [29].

Smart grids are energy grids that intelligently integrate the actions of all the users connected to it (prosumers, consumers, or both) to provide an economic and safe environment [30]. In this sense, the authorities are encouraged to follow this network revolution [8], where the function of these integrated systems is to protect the components of the electrical system, control the flow of energy, and monitor the process [6]. Therefore, the smart grid needs real-time information processing with communication support, as users' energy demands also change dynamically [31]. This requires a platform that provides secure communication, data storage services, and high computing power to handle a huge number of requests from multiple consumers [32]. With the help of the IoT and cloud computing, the demand requirements of the smart grid can be met.

\subsection{Internet of Things and Cloud Computing}

The IoT concept is directly linked to the concept of connected smart communities [33] once the IoT can improve the ability to collect, analyze, and render data [27]. Thus, research has been done to integrate the IoT with cloud computing to create an environment for energy management [27], where new value-added services related to energy are offered, which facilitate the integration of various energy sources and the automatic control of system operation [21]. In this sense, the management of information related to smart grids will be improved through its integration with cloud computing [31].

Cloud computing has an answer to this huge set of computing resources and storage needs of future energy systems [29]. The main principle of cloud computing is to distribute resources to a large number of computers or data centers, which meet the requirements of applications by shifting resources and giving access to the storage system when needed [31]. Cloud computing can manage the assets of the demand and supply curves, monitor the network assets online for cost optimization, and help the consumer for support payment, according to energy consumption, in addition to having an unlimited storage capacity of data [34].

\subsection{Energy Cloud}

The integration of electrical and information infrastructures is the basis of a cloud-based energy management system [35]. The energy cloud idea is to connect different end-users and promote coordination in excess electricity with the participation of these end-users, which can adjust their optimal storage capacity, according to energy consumption and generation [36]. The users' energy grid is connected to the public distribution network [7] and the automation devices for electrical systems are integrated into communication networks to exchange information between various devices and supervisory systems [6]. Reference [37] proposed that this cloud-based technology injects intelligence into the management of energy districts, which provides a distributed computing layer that controls 
the physical devices of end-users, and interacts with a centralized cloud component that manages the entire district.

The Energy Cloud offers the technical and economic conditions to support the generation of distributed energy and the activation of demand response programs based on four main premises [7]: (i) new regulations on electricity generation, (ii) the decrease in the cost of distributed energy resource technologies, (iii) energy consumers, which are becoming more active and receptive to the problem of electricity consumption, and (iv) the development of smart grid infrastructure is already mature enough to support the digitalization of the energy grid. Thus, it is evident that the integration of the IoT and cloud computing with energy management systems has enabled greater autonomy for users concerning monitoring, control, and management of their energy networks and devices, which gives rise to the energy cloud.

\section{Materials and Methods}

This research was developed through a systematic review (SR) and an analysis based on a bibliometric analysis tool. A systematic literature review aims to answer research questions that increase the knowledge in a research field for researchers, policymakers, and other users [38], and to be able to select relevant articles and obtain consistent data on a theme. The establishment of a research protocol is crucial [39]. Therefore, the Preferred Reporting Items for Systematic Reviews and Meta-Analyses (PRISMA) declaration was used as a protocol that provides credibility for the selection of research to be included in the SR. PRISMA consists of a checklist with four phases focused on ensuring transparency and reliable reporting of results [40].

In the PRISMA identification phase, search strings need to be defined. Thus, since this article aims to present the basic elements and requirements for energy cloud and its management, and discuss the main challenges and opportunities related to managing this environment, the choice of keywords was thought to retrieve a diversity of research that can include a broad scope of themes related to the energy cloud and its management. Therefore, the keywords searched in databases were "energy*" AND "cloud*" AND "management." The words cloud and energy were added with an asterisk (*) as a way of covering words with the same radical but different endings. The subject of this research has a multidisciplinary characteristic, which permeates different research areas such as energy, engineering, computer science, information technology, telecommunications, and management sciences. In this way, the keywords were tested in different databases to find out which ones were more appropriate and, with a broader scope, meet the research needs. Thus, it was found that Scopus, Web of Science, and Institute of Electrical and Electronic Engineers (IEEE) were the most appropriate databases for retrieving research on the subject. Moreover, considering that research related to this subject is being developed quickly, it was defined that both articles and conference papers would be analyzed. The subject areas were selected to cover all those research topics that may indicate elements, activities, challenges, and opportunities related to the theme. Therefore, the areas related to energy, engineering, computer science, and management were placed as a filter. The period filter was set for all years. Lastly, it was selected to search in the title, abstract, or keywords in Scopus, a topic in Web of Science, and all metadata in IEEE. Table 1 summarizes the search filters and Table 2 shows the Boolean criteria used to retrieve articles from Scopus, IEEE, and Web of Science databases.

The keywords and search filters were applied to the databases, and, initially, 9621 articles and conference papers were identified in the sum of the three databases. In the identification phase, duplicate records were also removed, which results in 7895 articles and conference papers. 
Table 1. Search filters.

\begin{tabular}{|c|c|c|c|}
\hline Filter & Scopus & Web of Science & IEEE \\
\hline Document type & $\begin{array}{c}\text { Articles OR } \\
\text { Conference Papers }\end{array}$ & Articles OR Proceedings & Journals OR Conferences \\
\hline Search in & $\begin{array}{l}\text { Title, abstract } \\
\text { or keywords }\end{array}$ & Topic & All Metadata \\
\hline Subject areas & $\begin{array}{l}\text { Computer Science; } \\
\text { Energy; Engineering; } \\
\text { Decision Sciences; } \\
\text { Business, Management } \\
\text { and Accounting; } \\
\text { Economics, Econometrics } \\
\text { and Finance }\end{array}$ & $\begin{array}{c}\text { Energy Fuels; Engineering } \\
\text { Electrical Electronic; Computer } \\
\text { Science Information Systems; } \\
\text { Computer Science Artificial } \\
\text { Intelligence; Green Sustainable } \\
\text { Science Technology; Engineering } \\
\text { Industrial; Engineering } \\
\text { Environmental; Engineering } \\
\text { Manufacturing; Engineering } \\
\text { Multidisciplinary; Business; } \\
\text { Economics; Management }\end{array}$ & All \\
\hline Years & All & All & All \\
\hline Search terms & $\begin{array}{l}\text { "energy" AND "cloud" } \\
\text { AND "management" }\end{array}$ & $\begin{array}{l}\text { "energy" AND "cloud" } \\
\text { AND "management" }\end{array}$ & $\begin{array}{l}\text { "energy" }{ }^{*} \text { AND "cloud"” } \\
\text { AND "management" }\end{array}$ \\
\hline
\end{tabular}

Table 2. Boolean criteria.

\begin{tabular}{|c|c|}
\hline Databases & Boolean Criteria \\
\hline Scopus & $\begin{array}{l}\text { (TITLE-ABS-KEY (“energy*”) AND TITLE-ABS-KEY (“cloud*”) AND TITLE-ABS-KEY } \\
\text { (management)) AND (LIMIT-TO ( DOCTYPE, “ar") OR LIMIT-TO (DOCTYPE, “cp”)) } \\
\text { AND (LIMIT-TO (SUBJAREA, “COMP”) OR LIMIT-TO (SUBJAREA, “ENGI”) OR } \\
\text { LIMIT-TO (SUBJAREA, “ENER") OR LIMIT-TO (SUBJAREA, “BUSI”) OR LIMIT-TO } \\
\text { (SUBJAREA, “DECI") OR LIMIT-TO (SUBJAREA, “ECON”)) }\end{array}$ \\
\hline Web of Science & $\begin{array}{l}\text { TOPIC: ("energy"”) AND TOPIC: (“cloud*”) AND TOPIC: (management) } \\
\text { Refined by: DOCUMENT TYPES: (ARTICLE OR PROCEEDINGS PAPER) AND WEB OF } \\
\text { SCIENCE CATEGORIES: (ENGINEERING ELECTRICAL ELECTRONIC OR BUSINESS } \\
\text { OR COMPUTER SCIENCE INFORMATION SYSTEMS OR ENERGY FUELS OR } \\
\text { ENGINEERING MANUFACTURING OR COMPUTER SCIENCE ARTIFICIAL } \\
\text { INTELLIGENCE OR GREEN SUSTAINABLE SCIENCE TECHNOLOGY OR } \\
\text { ENGINEERING MULTIDISCIPLINARY OR MANAGEMENT OR ENGINEERING } \\
\text { INDUSTRIAL OR ECONOMICS OR ENGINEERING ENVIRONMENTAL) } \\
\text { Timespan: All years. Indexes: SCI-EXPANDED, SSCI, A\&HCI, CPCI-S, CPCI-SSH, ESCI. }\end{array}$ \\
\hline IEEE & $\begin{array}{l}\text { (((“All Metadata":"energy") AND “All Metadata":"cloud*”) AND “All } \\
\text { Metadata":management) } \\
\text { Filters Applied: Conferences Journals }\end{array}$ \\
\hline
\end{tabular}

In the screening phase, the titles and abstracts were read and analyzed and 246 pieces of research were screened, excluding 7649 that did not contain, in the titles or abstracts, elements that could be related to the subject of this research. In the third phase of these 246 articles and conference papers, 159 were selected for eligibility and 87 were excluded who were not related to the subject of this research. Of these 87,15 were not recoverable and 72 pieces of research did not present an approach integrating the concepts of energy and cloud computing, nor relating energy and management, which is, therefore, excluded. Lastly, in the fourth phase, 144 articles and conferences were included in the quantitative and qualitative synthesis because they are related to the themes of energy, cloud, and management, which presents elements that enable the integration of these concepts by showing the evolution of energy management to the cloud environment, and indicates requirements for its development and diffusion. Figure 1 presents the PRISMA statement flow diagram used in this study. 


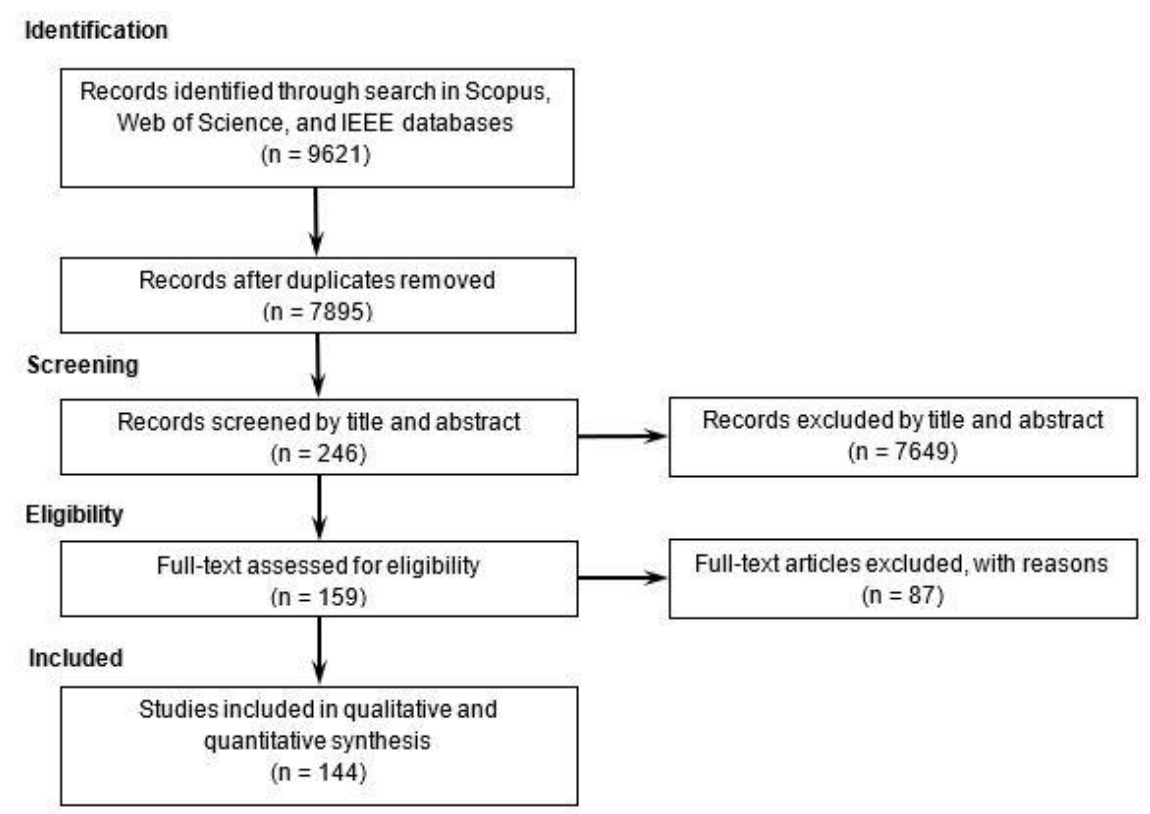

Figure 1. PRISMA statement flow diagram.

The 144 articles and conference papers included in the SR were catalogued and numbered in Microsoft Excel. The years of publication of the articles and conference papers researches included in the qualitative and quantitative synthesis are shown in Table 3.

Table 3. Number of studies per year included in the synthesis.

\begin{tabular}{cccc}
\hline Year & Number of Research Studies & Year & Number of Research Studies \\
\hline 2020 & 2 & 2014 & 3 \\
2019 & 46 & 2013 & 4 \\
2018 & 36 & 2012 & 4 \\
2017 & 12 & 2011 & 2 \\
2016 & 17 & 2010 & 1 \\
2015 & 17 & & \\
\hline
\end{tabular}

With the first reading of the conference papers and documents, it was identified that the layout format for energy cloud and its management most frequently addressed follows a trend of elements and requirements structured in layers and management support blocks (detailed in Section 4). From this, tables were created with one for each layer or support block to record all the elements and/or activities that make up each one as well as to record the challenges and opportunities related to each layer or support block. With this, it was possible to structure the layout for the energy cloud and its management, and to present the basic elements in Sections 5 and 6 by discussing the challenges and opportunities related to each layer or management support block mentioned in the layout.

To support the results obtained with the development of SR, a network of word co-occurrences [41] was created using the bibliometric software VOSviewer [42]. For that, the files with 144 articles and conference papers were downloaded in '.isi' and '.csv' format from the databases. The parameters used in the VOSviewer for the map generation were: (i) "Create a map based on bibliographic data"; (ii) "Read data from bibliographic database files"; (iii) "Select files"; (iv) "Choose type of analysis and counting method: Type of analysis - Co-occurrence; Counting method-Full counting; Unit of analysis-All keywords; (v) "Choose threshold": Minimum number of occurrences of a keyword: 6; (vi) "Choose number of keywords": Number of keywords to be selected: 31 (31 was the total number); (vii) "Verify selected keywords": All keywords were selected. The network of word co-occurrences is discussed and presented in Section 4. 


\section{Energy Cloud Management}

The energy cloud is a scalable and real-time energy management system that monitors and analyzes real or simulated energy data [20] in a dynamic environment [2] through the centralization of the management core in the cloud server by connecting all related actuators and sensors over the Internet to control energy savings [15]. Thus, the energy cloud allows a dynamic integration of different technologies in a smart grid environment. In this sense, Reference [7] shows an experiment with an energy community management model and concluded that this cloud-based energy community environment provides users with an active role in the energy market in addition to being an effective way to integrate renewable energy sources to the electricity grid. Similarly, Reference [43] presented a project of an energy cloud for energy-saving developed in Kaohsiung City in Taiwan, and concluded that this system provides users with an ability to realize a cause and effect analysis relating their needs and energy savings in addition to being an interactive platform for energy-saving information. Experiences like these show the potential of the energy cloud to integrate energy users, which provides benefits such as energy savings, dynamic performance in the energy market, and energy monitoring in real-time. From this, it can be seen that there is a need to manage these cloud-based energy environments to ensure that this system provides all the benefits it proposes.

Taking this into account, the Energy Cloud Management (ECM) environment should be designed to maximize energy self-consumption as well as users' profits and savings with the aid of a specific hardware and software architecture [7]. It must be structured to serve a wide variety of systems such as smart buildings, demand-side management, smart homes, demand response, and others [44] by providing a user-oriented management service [19] and value-added services and operations [45]. Therefore, it is possible to visualize the importance of a heterogeneous application capacity, which leads to the need for a robust systematization with a range of elements and activities capable of satisfactorily meeting the most varied needs.

Based on the analysis of articles and conference papers retrieved in SR, it can be seen that there is no consensus among the authors about the layout that best represents and that allows the distribution of all elements and activities necessary to compose the energy cloud system. However, studies $[8,14,27,46,47]$ structured the layout in the format of layers and blocks with at least five layers or blocks in each article, while the other articles of SR presented fewer layers, different layouts, or they limited themselves to discussing more specific points concerning the theme addressed in this article. In this sense, Reference [27] proposed a fog computing framework for energy management in a smart building. In Reference [8], the authors researched the use of cloud computing in the energy management of smart grids. In Reference [46], the authors proposed a new layered architecture for big-data-driven smart homes. In Reference [47], the researchers designed a system of the IoT for residential smart grids, and Reference [14] researched the management of smart grid information in the cloud. From these studies, it can be deduced that cloud-based energy management systems can be structured in layers in which each layer has elements responsible for certain activities necessary for this management to happen efficiently.

Other retrieved research that consistently addresses elements that may refer to the structure of layers and blocks. These studies relate the use of data systems to energy management in certain situations or environments. For example, Reference [48] proposed a micro forecasting module for energy management in residential environments. In Reference [49], the authors used data management and cloud computing to propose a user-aware power regulatory model with location-based service selection. In Reference [50], authors implemented a cloud analytics-assisted smart power meter for smart homes. Authors from Reference [51] presented a cloud system architecture to estimate the total cost of virtual machines based on resource use and energy consumption. Reference [52] discussed the feasibility of monitoring renewable energy in smart grids through cloud computing. 
From these studies, it is evident that the approaches already presented do not cover energy systems and information flows for their management as a whole once they address energy management with support from data cloud for specific environments such as smart buildings, smart homes, smart grids, microgrids, electric vehicles, energy districts, and shared communities, among others. Thus, to carry out an approach in a macro view of the energy management, it was necessary to identify and structure, based on previous research, a layout that can broadly represent the energy cloud system, and that can serve as a parameter for further research on this environment to be developed.

Thus, in this research, the layout was structured in layers and support blocks for ECM since it allows a clear discernment of the elements and activities developed in each of the layers or blocks by facilitating the direction of management activities. In this sense, for the approach developed in this article, the layout for the energy cloud is composed of seven layers that make up the physical and data system itself. Since the physical installations of generation, storage, and energy consumption pass through the communication links with the cloud, the transformation of data into knowledge useful for decision-making takes place. The existence of four management support blocks that aim to help in managing related issues from the seven principal layers was also identified by performing activities ranging from support in activities related to the energy market, through security, privacy, and auditing of data and information, to services performed by third parties in facilities and data and information processing systems.

Table 4 presents all the references from SR where one or more layers or support blocks considering those elements can be found, which can be directly related to the existence of these layers or support blocks by taking into account frameworks, schemes, maps, structures, layouts, architectures, and other representations found in retrieved research.

Table 4. References on layers and support block for energy cloud management layout.

\begin{tabular}{cccc}
\hline Number & Type & Layer & References \\
\hline 1 & Principal layer & PHYSICAL & {$[2,3,5,7,8,12-14,19,25-29,31-33,46-48,50,53-81]$} \\
2 & Principal layer & FOG & {$[2,3,7,17,26,27,32,33,35,46-48,51,57-60,68,69,71,72,74-76,82]$} \\
3 & Principal layer & NETWORK & {$[5,27,35,46-48,56,59,65,67,74,79,82-84]$} \\
4 & Principal layer & CLOUD & {$[2,3,7,8,12-14,17,19,20,25-29,31,33,35,46-48,50,52-55,57,59-65,68,69,71-73,76,78-83,85-88]$} \\
5 & Principal layer & SERVICE & {$[2,8,12,20,25,27,46-52,54,55,58,63,70,71,81,84,89]$} \\
6 & Principal layer & SESSION & {$[13,27,46,51,81,84]$} \\
7 & Principal layer & APPLICATION & {$[8,12,14,20,25,27,29,31,46,47,50-56,61-63,67,70,71,74-76,80,84,86-90]$} \\
8 & Support block & BROKER & {$[5,14,50-52,66,75,85,87]$} \\
9 & Support block & SECURITY & {$[14,49,52,91]$} \\
& & AND PRIVACY & {$[13,49,52]$} \\
10 & Support block & CLOUD & {$[8,14,50,81,92]$} \\
& & AUDITOR & \\
\hline
\end{tabular}

Figure 2 shows the layout for the ECM disposing of the seven principal layers with one on top of the other in gradient tones, which indicates that the flow of data and information can have two directions, from bottom to top and from top to bottom, while the four blocks of support activities were positioned in the surroundings, which symbolizes that each auxiliary activity can be developed within any of the seven main layers.

To check and compare with the layout shown in Figure 2, a bibliometric analysis was performed with the VOSviewer software. The metadata of the articles included in the systematic review were used to generate Figure 3. In this figure, an aggregation of words in three predominant colors of red, green, and blue are shown. The terms presented in the figure in red colors, such as the IoT, fog computing, IoT, fog, renewable energy resources, and smart buildings, represent elements that make up the layers of data collection and aggregation in Figure 2, which are the physical and fog layers. The terms 'energy management' in a red color and 'cloud computing' in a green color, in the center of the graph and linked to all the other terms in the graph, bring an understanding that the main theme of the research articles addresses energy management, bringing a direct relationship with cloud computing. The terms represented in Figure 3 in a green color in predominantly aggregate elements of the intermediate layer 
cloud and service, where the data are stored, handled, and processed to generate relevant information, will assist in the decision-making related to energy. In this sense, the following terms: cloud computing, digital storage, big data, data handling, green computing, smart grid, and smart power grids can be related. In a blue color, terms such as energy management systems, energy efficiency, and optimization, which can be related to the application layer, where users manage their energy system. The term 'demand-side management' is alone in a yellow color but is also directly linked to the following terms: energy management, cloud computing, and smart grid. This analysis leads to the understanding that the layered structure for energy cloud management can satisfactorily represent this environment for energy management, and, in addition to the basic structure, it still receives support from the four management support blocks presented.

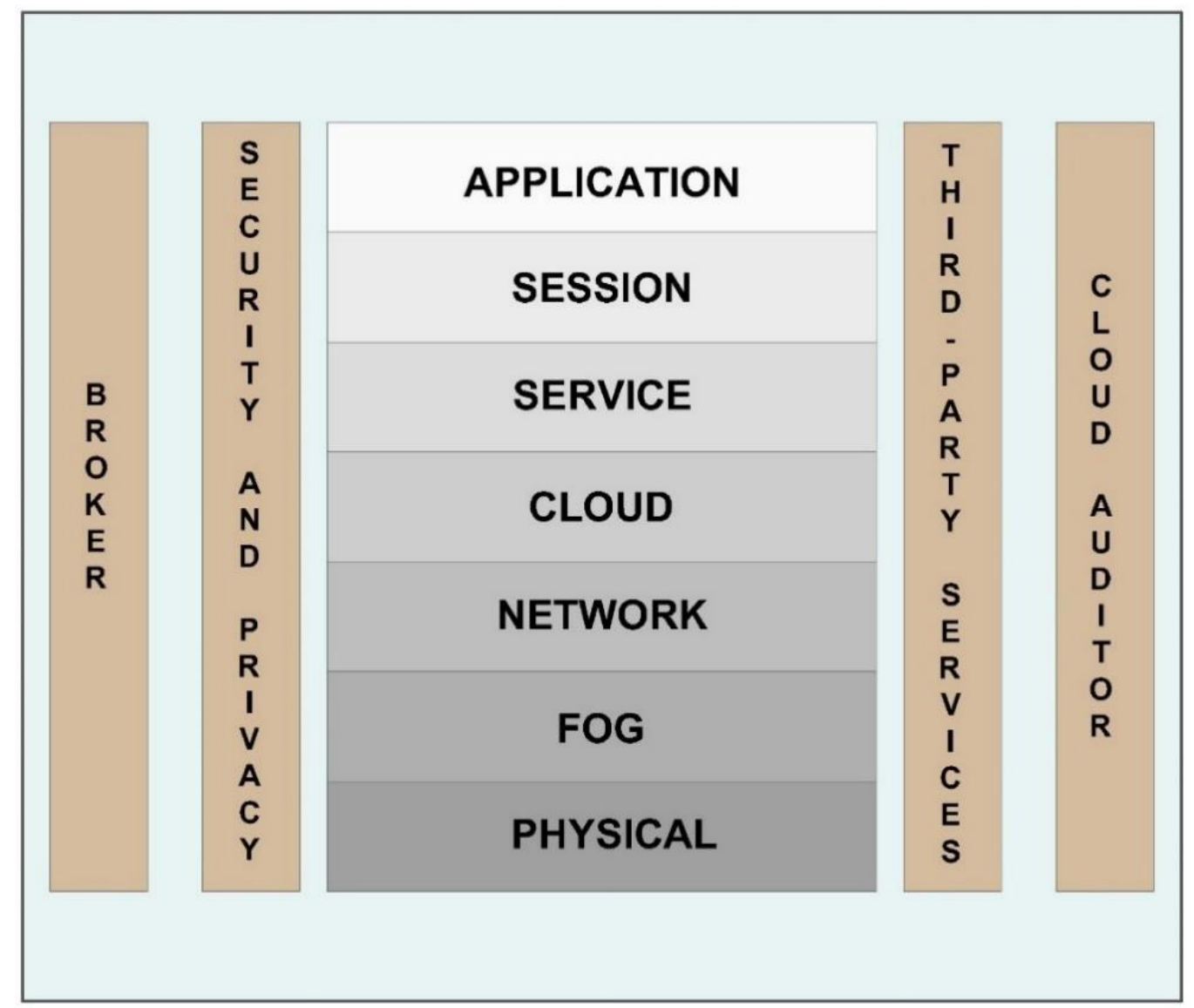

Figure 2. Energy cloud management layout.

For the ECM environment to be properly implemented, several key points need to be addressed. Among the points cited in the research retrieved from the SR, the following are mainly mentioned: the scalability of technological and computational solutions, interoperability between devices from different manufacturers and technologies, the reliability and confidentiality that these systems can offer users, the flexibility to serve users in a customized manner, the quality of services, the efficiency of the system, the level of application availability, the minimization of costs for the implementation and use of systems, the decrease in communication latency, the increase in investments in infrastructure, and a capacity for rapid elasticity of systems. The fulfillment of these points depends on several factors with considerable criticality presented and discussed in Sections 5 and 6. 


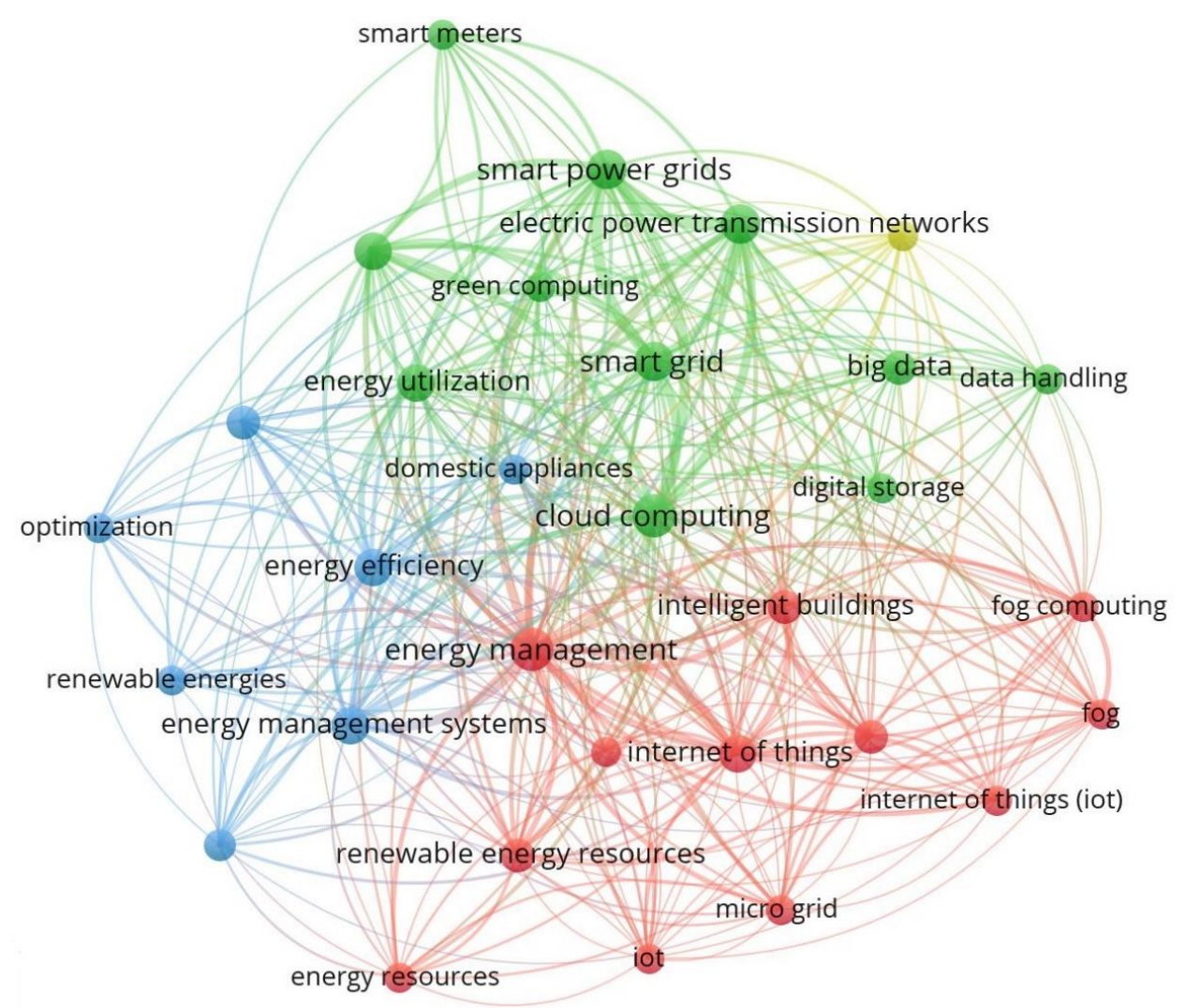

Figure 3. Bibliometric analysis.

\section{Principal Layers}

Each of the seven main layers requires a series of elements and activities to be developed so that data and information can go from the physical installations, where the data is captured, to the application layer, where decisions are made on energy management systems. In this decision-making environment, the command signals are sent back to the physical installations by increasing or decreasing generation or storage, performing tasks on consumer devices, and requesting the purchase or sale of energy, among other related activities. Table 5 presents the basic elements found in the SR by dividing them between the main layers. It is worth noting that the elements listed in the table are a compilation of elements found in the articles of the SR. Therefore, there may be more elements that can still be listed but that are not listed here.

In the following subsections, the seven layers are detailed, and the main challenges and opportunities for their development are discussed.

\subsection{Physical}

The physical layer includes the main types of sensing technologies and devices installed, such as smart appliances, comfort systems, consumption devices, energy generation, electric vehicles, energy storage installations, and energy meters $[9,14,46]$. In short, any infrastructure capable of generating, transmitting, distributing, storing, or consuming electricity can be included in this layer. In the energy cloud environment, these physical infrastructures contain sensors and actuators connected to the Internet through IoT technology by enabling the collection and transmission of real-time data related to the operation of these physical infrastructures. 
Table 5. Layers elements.

LAYERS

PHYSICAL

FOG

NETWORK

CLOUD

\section{ELEMENTS}

Distributed energy generation resources

Bulk generation

Energy storages systems

Electric vehicles

Parking lot or charging stations

Power consumption devices

Sensors and IoT devices

Instrumentation for monitoring and control

Energy transmission and distribution installations

Smart meters

GIS (Geographic Information System)

Energy hubs

Microgrids

Sensors hubs

Data concentrators

Local processing system

Fog servers

Cloud service support

Communication service support

Remote terminal unit (RTU)

Communication converters

Gateways and routers

Ethernet, Wi-Fi, bluetooth, USB and serial communication

Communication protocols (M2M; MQTT; Modbus; Internet; RS-485/232)

ICT (Information and Communication Technology)

$$
\text { ZigBee gateway }
$$

2G, 3G, 4G, 5G, GPRS/CDMA, and GSM networks

$$
\text { WiMAX }
$$

RFID - Radio frequency identifications optical networks

Communications in the vehicular environment: V2V; V2I; VANET;

Cloud gateway

GPS (Global Positioning System)

Communications networks devices

Data flow management systems

Datacenter and storage units

Real-time data processing systems

Batch data processing systems

Public, private, hybrid, regional, and community cloud

Data acquisition

Distributed data storage

Data storage: Data clustering, replication, and indexing

Programming models

Abstract logic

Open source operating system 
Table 5. Cont.

\begin{tabular}{cc}
\hline LAYERS & ELEMENTS \\
\hline SERVICE & Devices for real-time data visualization \\
Analytical data analysis \\
Power generation forecasting \\
Knowledge-based systems \\
Pattern management \\
Big data \\
Data pre-processing: Cleaning and transmission \\
Data processing: Prediction and classification \\
Optimization algorithms \\
Web-based information technology \\
HTTP (Hypertext Transfer Protocol) \\
APIs (Application Programming Interface) \\
CoAP (Constrained Application Protocol) \\
MQTT (Message Queue Telemetry Transport) \\
XMPP (Extensible Messaging and Presence Protocol) \\
Smartphone application login identify \\
WebSockets \\
\hline PresSION \\
Pre-operation, real-time operation, post-operation of transmission and distribution systems \\
Mobile devices \\
EMS (Energy Management Systems) \\
WebApps \\
Dashboards \\
Services creation, analysis, and management \\
Virtual energy storage \\
Configuration management \\
\hline
\end{tabular}

The integration and interconnection of these infrastructures, sensors, and actuators with the cloud depend on basic requirements such as interoperability between devices, high energy quality, systemic efficiency, versatility, controllability, resilience, mobility, and reduced cost for joining and installation for different types of users. Thus, considering that the basic infrastructure of this layer contains installations for generation, transmission, and distribution of energy, renovation, and automation $[6,13]$ as well as improvements in protection systems [6,31], which are the main technological and economic challenges to overcome. Regarding energy storage systems, the main challenges are the high value of initial investment [36,77] and the short life cycle of batteries [93]. Concerning electric vehicles, three important opportunities for technological development are the optimization of energy consumption by electric vehicles [94], the installation of a greater number of charging points [95], and the addition of renewable energy in these charging stations [96].

Concerning the considerable increase in the use of sensors in devices and installations [46] as well as the IoT integration in distributed generation installations and energy consumption devices, one of the main challenges to overcome is the reduction of costs, the reduction of energy consumption, the incorporation of technological improvements, and easier maintenance of these IoT devices [32,59,72]. It would be relevant to standardize the hardware and software of IoT devices using public domain standards [59]. The systematization of techniques for forecasting distributed energy generation can be added to the opportunities to be explored [97], which can enable greater autonomy and planning for system users. In addition, the evolution and transition from energy management to a data cloud environment depend on greater control over energy waste [67] and regulation of energy exchange between end-users [36].

\subsection{Fog}

The fog layer can also be called the edge layer. This layer includes all those elements that have the characteristic of concentrating the data received from the IoT devices and preparing them to send to the cloud such as sensor hubs, data concentrators, local processing systems, remote terminal units, routers, 
gateways, and others listed in Table 5. Fog computing provides flexibility, data privacy, interoperability, and real-time energy management [60] through the storage and computing close to the end devices by performing light computing tasks that can happen at the edge by decreasing latency $[27,46]$, and, thereby, decreasing the load on the cloud $[5,98]$. In practice, these devices receive and, with the aid of algorithms, make the initial filter of the data generated by the sensors and IoT devices by performing the first computational tasks of data aggregation and preparing them to be sent through the network to the cloud. Thus, fog servers are closer to the data collection points, which is an interface layer between physical devices and distant cloud data centers [27,98].

Fog servers have the function of being a layer that interconnects the others by catalyzing the data collected from the devices. Because of this, the response time of fog servers must be as short as possible $[46,68,72,98]$, and they must have adequate computational power [57] together with a temporary data storage capacity for that user's data, which can be stored there temporarily when the cloud is out of operation [26]. Another important task to be highlighted is that there must be a selection of the data that will be sent to the cloud, which relieves the data transmission networks [46,57]. However, perhaps one of the challenges that most impacts the companies that manufacture the components of this layer is the need for convergence toward standardization, which makes it possible to integrate different technologies and devices $[16,17,59,99]$ by bringing facilities to users, companies, and service providers as well as contributing to the dissemination and use of the concept of ECM.

\subsection{Network}

The network layer includes all the communication networks such as mobile, ad-hoc, and home, gateways, and communication protocols listed in Table 5. These technologies are used to transfer the data from the fog to the cloud layer for further processing $[27,46]$, and this data transmission occurs over a long distance, from users' domains to where the cloud data centers are located. Thus, since the network saturation level is a constant concern $[57,82,98,99]$, it is important to choose a communication medium with appropriate bandwidth for a large amount of data transportation between fog and cloud layers [98]. Considering this concern and the mobile network technologies available, such as Second Generation (2G), Third Generation (3G), Fourth Generation (4G), Fifth Generation (5G), General Packet Radio Service/Code Division Multiple Access (GPRS/CDMA), and Global System for Mobile Communication (GSM), improvements in connectivity levels and mobility of data and communications networks are important challenges related to networks to be overcome $[50,53,82]$. Following the same idea, the connectivity of electric vehicles to mobile networks is an opportunity that needs to be further developed by companies [83,100].

In addition, to achieve a high level of interoperability between devices from different manufacturers [46,67], contributing to the integrity and volume of data and information transmitted [67], an important challenge to be overcome is the standardization of communication protocols and technologies $[46,67,101]$ that may also contribute to significant improvements in data communication between the lower layers and the cloud. Other challenges to be overcome are a necessary reduction in the consumption of energy in communications [82] as well as a reduction in the cost of these communications [60].

\subsection{Cloud}

This layer provides data storage, management, and real-time processing in a computing environment that cannot be implemented at the fog $[14,27,46]$. For this, the cloud layer is composed of data flow management systems, data centers, and storage units, real-time data processing systems, and batch data processing systems [46]. In practice, all data that are collected in the physical layer and aggregated and pre-processed in the fog computing stage are sent over the network to be stored and processed in the cloud layer. Cloud data centers can be public, private, or hybrid, which facilitate accessibility to different types of users. Likewise, there may be community-shaped clouds or cooperatives created to make access to these services cheaper. Besides, the adhesion of users 
to public or private cloud services for storing energy-related data also depends on structuring pricing policies for the use of the cloud system where users pay for the system as they use it [51].

While the cloud platform makes it possible to externalize all measurements, store, analyze, and prepare data for other functions [48], there is a need to improve infrastructure and computational power of installations that fit this layer [32]. These improvements should also lead to lower energy consumption [10,51,102-106], and also decrease maintenance costs $[52,102,103,105,106]$. Other technological challenges cited by the authors that can contribute to the improvement of activities related to the cloud are the improvement of data collection and acquisition, and scheduling tasks to reduce data traffic in the cloud $[16,98,107]$, increase storage capacity, increase the number of users connected $[29,108]$, reduce cloud saturation bottlenecks $[33,53,59,60,69,72,98]$, improve data processing algorithms $[33,46,63]$, decrease server failures and loss of user data $[29,63]$, and integrate distributed data storage systems $[16,63]$.

\subsection{Service}

The service layer can also be called Big Data or analytics. The energy data are pre-processed by algorithms to transform, reduce, integrate, and clean data [12]. Then, there is the continuous processing of user data using the metadata available in the cloud as well as standardizing and making available the indicators in the format of operational data views and analytical data views, accessible at the moment the user wants to access those information [46]. A series of activities carried out in this layer make this analytical data visualization possible, such as data cleaning and transmission, data prediction and classification, pattern management, and power generation forecasting, among others. Therefore, this layer contains all elements and activities responsible for transforming the raw data from the physical layer into insights and indicators that will assist in the decision-making process related to energy management.

The definition of which data should be sent to the cloud directly interferes in the service layer, as it is based on the available data that statistical analysis on production, consumption, forecasts, and other analyses related to energy are carried out $[102,109,110]$, which shows the importance of integrating the activities of different layers. Because of all these data-related tasks, there is a need for implementation of improvements in the data pre-processing stage, such as the standardization of attributes and data format $[12,46,48]$, which can directly contribute to the data processing time $[19,46]$. This data processing time can still be reduced through investments in powerful and robust computing infrastructures for analysis of available data $[32,81,111]$ by transforming them into relevant information to aid decision-making.

Decision-making related to energy management must be carried out based on accurate information that faithfully reflects the reality found. Thus, the generation of information needs to be improved through techniques and algorithms [25] to manage, analyze, and transform the available data into relevant insights for users [17]. Another important point to be highlighted that can contribute to the standardization of services is the implementation of big data governance [112]. Lastly, as in the cloud layer, pricing policies can also be implemented in the provision of services in the pay-as-you-use for the users' mode [98].

\subsection{Session}

This layer provides standards and application programming interfaces (APIs) for exchange data between the service and application layers so that they do not have to be connected continuously [46]. This layer is composed of APIs and protocols such as Hypertext Transfer Protocol (HTTP), Extensible Messaging and Presence Protocol (XMPP), Message Queuing Telemetry Transport (MQTT), and Constrained Application Protocol (CoAP), and it intermediates the users' requests for data-related services in the service layer and its availability in the energy management system in the application layer. Some authors do not treat the session as a layer, but only as an interconnection between the service and application layers [47]. However, this layer makes it possible to obtain, monitor, and control 
the infrastructure through independent hardware [51], which is not part of the service or application layer elements.

The performance of the activities performed in this layer depends on a clear definition of the standard protocols and APIs and the scalability of solutions for the Uniform Resource Locator (URL) resources [46]. This performance also depends on user authentication algorithms [13], faster traffic, and information delivery $[47,112]$, which can be influenced by the Internet response time $[49,53,113]$. Lastly, an opportunity to be explored is to use social networks as a way to connect the service and application layers [28].

\subsection{Application}

The most visible layer to the end-users [52] includes all applications such as mobile devices, web apps, management dashboards, and energy management systems used in energy management based on information and insights generated in the service layer, which provides it on a friendly platform [27,46]. In this layer, user applications are described as virtual devices, formed by a set of interconnected virtual machines between them [51], and users can perform data analysis for making decisions accurately [9]. Thus, any form of user interaction with the physical energy systems occurs through this layer.

In the application layer, the main challenges and opportunities raised in SR start to have a more mixed focus by addressing technological issues, but important usability management issues were also raised. A point highlighted by several authors is the development and implementation of interactive dashboards for monitoring, control, and decision-making with a friendly interface customizable by users. This is easily manipulated by users from different areas of knowledge $[17,22,31,75,84,91,113]$. Taking this into account, the energy management dashboards must faithfully virtualize the installed physical infrastructure [78,87] and provide updated information in real-time [20,78] with low latency [56] by integrating the energy management system with the other layers and management support blocks, including the energy market in real-time [114]. An opportunity to be disseminated is the implementation of support for the mobility of energy management systems, which makes it possible to manage energy systems using mobile devices [115]. Similar to the other layers, it is also important to implement continuous improvements in algorithms that help in decision-making by users [116].

Considering that the diffusion of these systems seeks to reach users with different financial capacities, an important challenge in this layer is the minimization of costs and capital needed to facilitate the diffusion of energy management systems $[20,117]$ through the control and optimization of parameters by appropriately allocating resources $[65,70]$ to reach users with different financial capacities.

\section{Support Blocks}

The four support and management blocks are shown in Figure 2 (broker, security and privacy, third-party services, and cloud auditor) are responsible for carrying out activities complementary to those carried out in the main layers. These complementary and integration activities are characterized by the interaction of users with the system external to their domains, such as the energy market, the request for third-party services, tasks related to the security and privacy of their data, and auditing. Similar to Table 5, Table 6 also presents a compilation of the elements found in the SR and that can be distributed among the auxiliary management blocks. Therefore, there may be more elements that can still be listed but that are not listed here.

In the following subsections, the four supporting blocks are detailed, and the main challenges and opportunities for their development are discussed. 
Table 6. Support block elements.

\begin{tabular}{|c|c|}
\hline SUPPORT BLOCKS & ELEMENTS \\
\hline BROKER & $\begin{array}{c}\text { Energy purchase and sale intermediation } \\
\text { The interface between customer information and energy markets such as } \\
\text { price estimation and energy bill calculation } \\
\text { Energy Market } \\
\text { Pricing systems such as Real-time pricing (RTP), Time of Use (ToU), } \\
\text { or Critical Peak Pricing (CPP) } \\
\text { Aggregating agent and energy intermediary for electric vehicles } \\
\text { Cloud Energy Storage (CES) management } \\
\text { Fees for using resources such as equipment rental and maintenance of the } \\
\text { electricity grid infrastructure } \\
\text { Energy supply module and auxiliary services } \\
\text { Swing mechanism module for managing stochasticity } \\
\text { User management module with distributed energy resources } \\
\text { Community ecosystem broker } \\
\text { Business intelligence } \\
\text { Chatbots and Autonomous agents } \\
\text { Storage Market } \\
\text { Balancing Market }\end{array}$ \\
\hline SECURITY AND PRIVACY & $\begin{array}{l}\text { Data and information security management: Privacy, integrity, } \\
\text { confidentiality, and availability } \\
\text { Data and information privacy } \\
\text { SSL Protocols (Secure Sockets Layer) } \\
\text { Secure communication } \\
\text { Data and application protection } \\
\text { Secure Booting } \\
\text { Transparency and reliability of actions with data } \\
\text { User authentications and authorization controls } \\
\text { Firewalls } \\
\text { Attacks detection }\end{array}$ \\
\hline THIRD-PARTY SERVICES & $\begin{array}{c}\text { Installation and maintenance of systems and devices } \\
\text { Operational monitoring and maintenance services } \\
\text { Additional services such as transport, information for system operators, } \\
\text { healthcare, weather forecast, government announcements, consultation with } \\
\text { the legislation, accounting, emergency, etc. } \\
\text { Customer profiler } \\
\text { Services repository } \\
\text { Advisory services }\end{array}$ \\
\hline CLOUD AUDITOR & $\begin{array}{c}\text { Security systems audit } \\
\text { Privacy audit } \\
\text { Performance audit } \\
\text { User authentication and identity management } \\
\text { Certification of renewable generation resources }\end{array}$ \\
\hline
\end{tabular}

\subsection{Broker}

Characterized as a support block for the management of the energy cloud, the broker encompasses tasks such as service intermediation, service aggregation, and service arbitrage [52], which helps in the purchase and sale of assets by providing information support for price analysis and optimization, which balances the supply and demand and energy trade between generators, utilities, distribution, and transmission operators and customers [14]. To fulfill these tasks, the broker includes all the elements and activities necessary for energy trading and must also be connected to the users' energy management applications. Thus, the energy market, storage market, and balancing market are part of the broker. To operate in these markets, users can make use of elements that can be offered by other companies, such as intermediation of energy purchase and sale, management of cloud energy storage, community ecosystem broker, business intelligence, chatbots, and autonomous agents. The pricing 
systems such as real-time pricing (RTP), time of use (ToU), and critical peak pricing (CPP), and the fees for using resources, such as equipment rental and maintenance of the electricity grid infrastructure, can all be included in the broker.

In broker systems, price communication and notifications to consumers must take place in real-time [8,82]. In this way, the information is collected and managed through an interface based on key performance indicators (KPIs) by providing the market information directed to the user [51]. Due to this, a serious problem to be faced is the communication delay between the Broker-Cloud-Application due to the long distance of data transmission [5]. Some means that can be used to assist in the agility of service to users are to use automated response systems for users, such as autonomous agents and chatbots [113], and use software for automatic verification of the user default [49].

The main financial return of the companies that will act in the broker environment will be through the pricing of the fees for using storage services and the fees for energy transaction services [118]. However, other important opportunities can be related to the centralizing of additional activities, such as the integration of centralized energy monitoring, building control, and security systems, and vehicle battery charge level $[45,113]$.

The evolution of current energy management systems to an ECM system also depends on evolution in the energy markets, which should have greater freedom, decentralization, dynamicity, and are without intermediaries $[67,113]$. Among the options for this evolution, the creation of cooperative systems can be cited so that users have greater negotiating power in the electricity market [7], and also have a decrease in marginal costs in the purchase and sale of energy from virtual power plants (VPP) [85] by taking into account that the optimal cost is when all devices are operating under ideal technical and safety conditions [48]. Concerning the price, in addition to the use of price as a tool for controlling energy consumption [66], the creation of dynamic electricity tariffs $[14,29,32,46,47,65,119,120]$ may also contribute to the solidification of the ECM systems.

\subsection{Security and Privacy}

Due to the complexity, interdependence, and connectivity of the ECM system [9], there is a need to ensure information security, privacy, and quality of services for the ECM environment [14]. This function is carried out by the elements and activities that compose the security and privacy support block, such as data and information security management, data and application protection, Secure Sockets Layer (SSL) protocols, secure booting, user authentications, authorization controls, firewalls, and attacks detection, among others. These activities permeate all other layers and support blocks to provide security and privacy to users regarding the data and information circulating in the energy cloud.

To ensure that these requirements are met, security and privacy issues can be done through secret keys in a dynamic process for each reading, which is destroyed when the users log off the systems [49] and remain active only while using the system, which ensures a greater sense of security for users. Other ways to provide security and privacy to users of the ECM system are the introduction of firewalls without compromising performance or increasing latency between layers $[22,59,98]$ to maintain the computational capacity of control and security systems even with encrypted data [49,91,121], a constant cost reduction, and optimization of data encryption algorithms [22,76,78,122,123] to provide an efficient user authentication system [17] that makes it possible to identify illegal activities [13] to detect data mix or leak and virtual attacks $[8,9,16,31,67,75,124,125]$ while still maintaining system integrity and security status $[33,58]$.

With the data in third-party domains, there is a concern with the retention of copies of this data [9], which brings psychological impacts to users because they are making their data available for storage in locations outside their domains. T address these issues, there should be a plan for collecting data from users, especially regarding what data and at what time [102] in addition to disabling unsafe services and devices. These challenges can lead company managers to use private clouds [20]. Another way to overcome these challenges is to segregate users according to the desired level of security [49]. 


\subsection{Third-Party Services}

Third-Party Services block services, such as installation and maintenance of systems and devices, operational monitoring, and additional services are performed to support the business processes required by other players from the ecosystem [14]. To systematize the actions and services of third parties, there must be an integration between the systems of these service providers with the energy management system [46]. Thus, considering the broad scope of activities listed in Table 6 and that these activities are delivered directly to end-users, there can be a customization of the services offered and provided, according to the needs of users $[16,120]$ aligning the interests of service providers and users [102] by establishing maintenance policies and strategies [70,126]. Additionally, there must be training for professionals who will carry out these activities $[98,126]$ by taking into account the technological interdisciplinarity of the elements that make up ECM [107]. Thus, as a way to maintain the quality of services [127], an opportunity to be explored is the establishment of collaborative networks between service providers by sharing information and market space [92], but maintaining ethical aspects in the provision of these services [102].

\subsection{Cloud Auditor}

This support block acts to audit the users' authentication system [49], and also includes security audits, privacy impact audits, and performance audits [52]. However, considering the integration of several technological elements and professional interdisciplinarity, there is a need to establish audit protocols in the operations to be carried out in the ECM environment [128] by seeking the transparency of the processes carried out in the cloud [112] and the energy market [85], which is always striving for maintenance of ethical aspects in this management system [102].

\section{Policy and Legislations Discussion}

Since the evolutionary trend of energy systems toward ECM layout is relatively recent, activities related to legislation and regulation of ECM were not presented as a layer or support block for management in any of the retrieved articles. However, some authors have expressed clear concerns about the need for regulatory bodies to establish policies and legislations for these activities. These concerns are about:

- The need to standardize the interoperability of the infrastructure [46,67];

- Regulation of energy sharing between users [32];

- Establishment of regulatory policies that evolve automatically over time [85];

- Establishing policies that define what data should be stored and how easily they can be accessed [112];

- Definition of privacy policies and user rights [16,75];

- Regulation of flow and storage of critical information [14];

- $\quad$ Regulation of a real-time energy market $[67,113]$.

From these concerns, which reflect the rapid evolution of energy systems with the integration of computational technologies, there is a need for greater agility in establishing and adapting policies and legislation regarding energy systems and markets. The lack of regulatory frameworks, especially concerning security and privacy policies, the flow and storage of critical information in the cloud, and the exchange of energy between users, can lead to a greater delay in the use and development of technologies for ECM, which can bring benefits to users, companies, countries, and the environment.

\section{Conclusions, Limitations, and Future Research}

The objective of this article was to present the basic elements and requirements for the energy cloud and its management and to discuss the main management challenges and opportunities for development and diffusion of the energy cloud. Considering this objective, the analysis of the articles 
and conference papers allowed us to identify that the layout that best represents the ECM environment is the layout in the layers' format, where the flow of information happens from bottom to top and from top to bottom. In addition to these layers, the existence of blocks to support ECM was also identified. The basic elements and requirements that compose the ECM environment have been identified with 70 basic elements or activities comprising the main energy cloud layers and 36 basic elements or activities integrating the support blocks for ECM. Several challenges and opportunities that can leverage ECM were pointed out and discussed. Thus, the objective of this article was achieved by identifying the layout for the energy cloud and its management, pointing out the basic requirements, and also discussing the challenges and opportunities for its development and diffusion.

Among the implications of this article, we highlight the layout developed to represent ECM environment, where the elements and activities are organized in seven main layers, which seek to represent the flow of data and information from the physical installations of the energy systems where the data is captured to the energy management systems where users interact with their energy systems. In addition to the main layers, four management support blocks were also represented. These support blocks seek to cover the complementary activities necessary to manage users' energy systems, such as the purchase, sale, and exchange of energy, the aggregation of third-party services that are necessary to the users' energy systems, security, and privacy in data and information flow as well as the audit of transactions, carried out. Therefore, with the layout presented and discussed, it was possible to present the basic elements and activities necessary for the ECM to researchers and entrepreneurs.

Considering the wide scope and the different areas of knowledge that make up the ECM layout and the discussions presented about the challenges and opportunities related to this environment, it is possible to state that there are opportunities to be developed by researchers and managers from different areas such as information technology, engineering, business management, and public management. This can be justified because, among the articles surveyed, the predominant references were about improvements in the robustness and power of communication and computer systems to support the volume increase in traffic and processing of data and, at the same time, decrease latency. It is also worth mentioning the importance of adopting devices with technological interoperability as well as reducing costs to make it possible to reach a greater part of the population. Highlighted improvements are developed for user authentication systems, integration of energy management systems with broker systems in a real-time energy market, regulation of this market in real-time, and integrated energy management systems with third-party services systems. Other needs were also identified concerning the creation and adaptation of policies and legislation to integrate energy cloud activities.

This article was limited to studying the elements and the main requirements for the development and consolidation of the energy cloud as a way to monitor and control energy systems. The approach used a managerial approach, seeking to indicate technological and managerial challenges to be overcome for the diffusion of ECM.

For future research, it is suggested to study the main challenges pointed out in this article and seek to outline strategies for meeting and implementing solutions that help overcome them. It is also suggested to structure a management model for the energy cloud by establishing connections and indicating the most appropriate paths to be followed to carry out ECM efficiently and effectively. Lastly, it would be relevant to develop diagnostic tools that can assess the technological maturity and management of localities for the implementation of the energy cloud technologies discussed in this study.

Author Contributions: Conceptualization, J.L.S., J.C.M.S., and J.R.P. Methodology, J.L.S., J.C.M.S., and P.S.d.C. Validation, J.L.S., J.C.M.S., and P.S.d.C. Formal analysis, J.L.S. and P.S.d.C. Investigation, J.L.S. Data curation, J.L.S. Writing—original draft preparation, J.L.S. and P.S.d.C. Writing-review and editing, J.C.M.S., P.S.d.C., J.R.P., and P.S.S. Supervision, J.C.M.S., J.R.P., and P.S.S. Project administration, J.C.M.S. All authors have read and agreed to the published version of the manuscript. 
Funding: The Conselho Nacional de Desenvolvimento Científico e Tecnológico (CNPq) [grant numbers 142448/2018-4, 308723/2017-1, 311926/2017-7 and 465640/2014-1], Coordenação de Aperfeiçoamento de Pessoal de Nível Superior (CAPES) [grant number 23038.000776/2017-54], and Fundação de Amparo à Pesquisa do Estado do Rio Grande do Sul (FAPERGS) [grant number 17/2551-0000517-1] supported this work. Schneider, P. S. received funding from the Conselho Nacional de Desenvolvimento Científico e Tecnológico (CNPq) [grant number PQ305357/2013-1]. The authors thank CNPq, CAPES, FAPERGS, and Institutos Nacionais de Ciência e Tecnologia-Geração Distribuída (INCT-GD) for supporting this research.

Acknowledgments: The authors thank Conselho Nacional de Desenvolvimento Científico e Tecnológico (CNPq), Coordenação de Aperfeiçoamento de Pessoal de Nível Superior (CAPES), Fundação de Amparo à Pesquisa do Estado do Rio Grande do Sul (FAPERGS), and Institutos Nacionais de Ciência e Tecnologia-Geração Distribuída (INCT-GD) for supporting this research.

Conflicts of Interest: The authors declare no conflict of interest. The funders had no role in the design of the study, in the collection, analyses, or interpretation of data, in the writing of the manuscript, or in the decision to publish the results.

\section{References}

1. Markovic, D.S.; Zivkovic, D.; Branovic, I.; Popovic, R.; Cvetkovic, D. Smart power grid and cloud computing. Renew. Sustain. Energy Rev. 2013, 24, 566-577. [CrossRef]

2. Dileep, G. A survey on smart grid technologies and applications. Renew. Energy 2020, 146, 2589-2625. [CrossRef]

3. Yue, J.; Hu, Z.; He, R.; Zhang, X.; Dulout, J.; Li, C.; Guerrero, J.M. Cloud-fog architecture based energy management and decision-making for next-generation distribution network with prosumers and internet of things devices. Appl. Sci. 2019, 9, 372. [CrossRef]

4. Sivapragash, C.; Thilaga, S.R.; Suresh Kumar, S. Advanced cloud computing in smart power grid. In Proceedings of the IET Chennai 3rd International Conference on Sustainable Energy and Intelligent Systems, Tiruchengode, India, 27-29 December 2012; Volume 2012, pp. 356-361.

5. Ruan, L.; Yan, Y.; Guo, S.; Wen, F.; Qiu, X. Priority-Based Residential Energy Management with Collaborative Edge and Cloud Computing. IEEE Trans. Ind. Inform. 2020, 16, 1848-1857. [CrossRef]

6. Waleed, A.; Virk, U.S.; Riaz, M.T.; Mehmood, S.B.; Ahmad, S.; Javed, M.R.; Raza, A. Effectiveness and comparison of digital substations over conventional substations. Adv. Sci. Technol. Eng. Syst. 2019, 4, 431-439. [CrossRef]

7. Giordano, A.; Mastroianni, C.; Sorrentino, N.; Menniti, D.; Pinnarelli, A. An energy community implementation: The unical energy cloud. Electronics 2019, 8, 1517. [CrossRef]

8. Allahvirdizadeh, Y.; Moghaddam, M.P.; Shayanfar, H. A survey on cloud computing in energy management of the smart grids. Int. Trans. Electr. Energy Syst. 2019, 29, e12094. [CrossRef]

9. Sookhak, M.; Tang, H.; He, Y.; Yu, F.R. Security and Privacy of Smart Cities: A Survey, Research Issues and Challenges. IEEE Commun. Surv. Tutor. 2019, 21, 1718-1743. [CrossRef]

10. Luo, P.; Wang, X.; Jin, H.; Li, Y.; Yang, X. Smart-grid-aware load regulation of multiple datacenters towards the variable generation of renewable energy. Appl. Sci. 2019, 9, 518. [CrossRef]

11. Geidl, M.; Koeppel, G.; Favre-Perrod, P.; Klöckl, B.; Andersson, G.; Fröhlich, K. Energy hubs for the future. IEEE Power Energy Mag. 2007, 5, 24-30. [CrossRef]

12. Ma, S.; Zhang, Y.; Lv, J.; Yang, H.; Wu, J. Energy-cyber-physical system enabled management for energy-intensive manufacturing industries. J. Clean. Prod. 2019, 226, 892-903. [CrossRef]

13. Kulkarni, N.; Lalitha, S.V.N.L.; Deokar, S.A. Real time control and monitoring of grid power systems using cloud computing. Int. J. Electr. Comput. Eng. 2019, 9, 941-949. [CrossRef]

14. Fang, X.; Misra, S.; Xue, G.; Yang, D. Managing smart grid information in the cloud: Opportunities, model, and applications. IEEE Netw. 2012, 26, 32-38. [CrossRef]

15. Cheng, C.-C.; Lee, D.; Wang, C.H.; Lin, S.F.; Chang, H.-P.; Fang, S.-T. The development of cloud energy management. Energies 2015, 8, 4357-4377. [CrossRef]

16. Bera, S.; Misra, S.; Rodrigues, J.J.P.C. Cloud Computing Applications for Smart Grid: A Survey. IEEE Trans. Parallel Distrib. Syst. 2015, 26, 1477-1494. [CrossRef]

17. Yassine, A.; Singh, S.; Hossain, M.S.; Muhammad, G. IoT big data analytics for smart homes with fog and cloud computing. Future Gener. Comput. Syst. 2019, 91, 563-573. [CrossRef] 
18. Swarna, S.P.; Bhattacharya, S.; Maddikunta, P.K.R.; Somayaji, S.R.K.; Lakshmanna, K.; Kaluri, R.; Hussien, A.; Gadekallu, T.R. Load balancing of energy cloud using wind driven and firefly algorithms in internet of everything. J. Parallel Distrib. Comput. 2020, 142, 16-26. [CrossRef]

19. Chen, Y.W.; Chang, J.M. EMaaS: Cloud-Based Energy Management Service for Distributed Renewable Energy Integration. IEEE Trans. Smart Grid 2015, 6, 2816-2824. [CrossRef]

20. Sequeira, H.; Carreira, P.; Goldschmidt, T.; Vorst, P. Energy cloud: Real-time cloud-native energy management system to monitor and analyze energy consumption in multiple industrial sites. In Proceedings of the 2014 IEEE/ACM 7th International Conference on Utility and Cloud Computing, London, UK, 8-11 December 2014; Institute of Electrical and Electronics Engineers Inc.: Piscataway, NJ, USA; pp. 529-534.

21. Liu, Y.; Yang, C.; Jiang, L.; Xie, S.; Zhang, Y. Intelligent Edge Computing for IoT-Based Energy Management in Smart Cities. IEEE Netw. 2019, 33, 111-117. [CrossRef]

22. Al Faruque, M.A.; Vatanparvar, K. Energy Management-as-a-Service over Fog Computing Platform. IEEE Internet Things J. 2016, 3, 161-169. [CrossRef]

23. Guo, Y.; Zhao, C. Islanding-aware robust energy management for microgrids. IEEE Trans. Smart Grid 2018, 9 , 1301-1309. [CrossRef]

24. Wang, Y.; Huang, Y.; Wang, Y.; Zeng, M.; Li, F.; Wang, Y.; Zhang, Y. Energy management of smart micro-grid with response loads and distributed generation considering demand response. J. Clean. Prod. 2018, 197, 1069-1083. [CrossRef]

25. Howell, S.K.; Wicaksono, H.; Yuce, B.; McGlinn, K.; Rezgui, Y. User Centered Neuro-Fuzzy Energy Management through Semantic-Based Optimization. IEEE Trans. Cybern. 2019, 49, 3278-3292. [CrossRef] [PubMed]

26. Sittón-Candanedo, I.; Alonso, R.S.; García, Ó.; Muñoz, L.; Rodríguez-González, S. Edge computing, iot and social computing in smart energy scenarios. Sensors 2019, 19, 3353. [CrossRef] [PubMed]

27. Maatoug, A.; Belalem, G.; Mahmoudi, S. Fog computing framework for location-based energy management in smart buildings. Multiagent Grid Syst. 2019, 15, 39-56. [CrossRef]

28. Qin, Y.B.; Housell, J.; Rodero, I. Cloud-based data analytics framework for autonomic smart grid management. In Proceedings of the 2014 International Conference on Cloud and Autonomic Computing, London, UK, 8-12 September 2014; Institute of Electrical and Electronics Engineers Inc.: Piscataway, NJ, USA, 2018; pp. 97-100.

29. Ma, Y.; Zhao, F.; Zhou, X.; Gao, Z. Summary of cloud computing technology in smart grid. In Proceedings of the 2018 IEEE International Conference on Mechatronics and Automation, ICMA 2018, Changchun, China, 5-8 August 2018; Institute of Electrical and Electronics Engineers Inc.: Piscataway, NJ, USA, 2018; pp. 253-258.

30. Salvadori, F.; Gehrke, C.S.; Hartmann, L.V.; De Freitas, I.S.; Santos, T.D.S.; Texeira, T.A. Design and implementation of a flexible intelligent electronic device for smart grid applications. In Proceedings of the 2017 IEEE Industry Applications Society Annual Meeting, IAS 2017, Cincinnati, OH, USA, 1-5 October 2017; Institute of Electrical and Electronics Engineers Inc.: Piscataway, NJ, USA, 2017; pp. 1-6.

31. Sami, I.; Ali, S.M.; Nazir, S.; Khan, I.; Asghar, R.; Abid, M.A.; Ullah, Z.; Khan, B.; Mehmood, C.A. Cloud Computing (CC) Centers-A Fast Processing Engine in Smart Grid. In Proceedings of the 1st International Conference on Electrical, Communication and Computer Engineering, ICECCE 2019, Swat, Pakistan, 24-25 July 2019; Institute of Electrical and Electronics Engineers Inc.: Piscataway, NJ, USA, 2019.

32. Khalid, A.; Aslam, S.; Aurangzeb, K.; Haider, S.I.; Ashraf, M.; Javaid, N. An efficient energy management approach using fog-as-a-service for sharing economy in a smart grid. Energies 2018, 11, 3500. [CrossRef]

33. Zahoor, S.; Javaid, S.; Javaid, N.; Ashraf, M.; Ishmanov, F.; Afzal, M.K. Cloud-fog-based smart grid model for efficient resource management. Sustainability 2018, 10, 2079. [CrossRef]

34. Cioara, T.; Anghel, I.; Salomie, I.; Antal, M.; Pop, C.; Bertoncini, M.; Arnone, D.; Pop, F. Exploiting data centres energy flexibility in smart cities: Business scenarios. Inf. Sci. 2019, 476, 392-412. [CrossRef]

35. Govindarajan, R.; Meikandasivam, S.; Vijayakumar, D. Cloud computing based smart energy monitoring system. Int. J. Sci. Technol. Res. 2019, 8, 886-890.

36. Li, S.; Yang, J.; Fang, J.; Liu, Z.; Zhang, H. Electricity scheduling optimisation based on energy cloud for residential microgrids. IET Renew. Power Gener. 2019, 13, 1105-1114. [CrossRef]

37. Burgio, A.; Giordano, A.; Manno, A.A.; Mastroianni, C.; Menniti, D.; Pinnarelli, A.; Scarcello, L.; Sorrentino, N.; Stillo, M. An IoT Approach for Smart Energy Districts. In Proceedings of the 2017 IEEE 14th International Conference on Networking, Sensing and Control (ICNSC), Calabria, Italy, 16-18 May 2017; pp. 146-151. [CrossRef] 
38. Can Şener, Ş.E.; Sharp, J.L.; Anctil, A. Factors impacting diverging paths of renewable energy: A review. Renew. Sustain. Energy Rev. 2018, 81, 2335-2342. [CrossRef]

39. Da Costa, M.B.; Dos Santos, L.M.A.L.; Schaefer, J.L.; Baierle, I.C.; Nara, E.O.B. Industry 4.0 technologies basic network identification. Scientometrics 2019, 121, 977-994. [CrossRef]

40. Liberati, A.; Altman, D.G.; Tetzlaff, J.; Mulrow, C.; Gøtzsche, P.C.; Ioannidis, J.P.A.; Clarke, M.; Devereaux, P.J.; Kleijnen, J.; Moher, D. The PRISMA statement for reporting systematic reviews and meta-analyses of studies that evaluate healthcare interventions: Explanation and elaboration. BMJ 2009, 339. [CrossRef] [PubMed]

41. Nara, E.O.B.; Schaefer, J.L.; de Moraes, J.; Tedesco, L.P.C.; Furtado, J.C.; Baierle, I.C. Sourcing research papers on small- and medium-sized enterprises' competitiveness: An approach based on authors' networks. Rev. Esp. Doc. Cient. 2019, 42,1-16. [CrossRef]

42. Van Eck, N.J.; Waltman, L. Software survey: VOSviewer, a computer program for bibliometric mapping. Scientometrics 2010, 84, 523-538. [CrossRef]

43. Chen, C.N.; Cho, M.Y.; Huang, H.Y. Development of Energy Cloud for Energy Saving of Kaohsiung City. In Proceedings of the 3rd International Conference on Green Technology and Sustainable Development, GTSD 2016, Kaohsiung, Taiwan, 24-25 November 2016; Institute of Electrical and Electronics Engineers Inc.: Piscataway, NJ, USA, 2016; pp. 39-44.

44. Naveen, P.; Kiing, W.; Michael, I.; Danquah, K.; Sidhu, A.S.; Abu-Siada, A. A Cloud Associated Smart Grid Admin Dashboard. Eng. Technol. Appl. Sci. Res. J. 2018, 8, 2241-4487.

45. Lee, Y.T.; Hsiao, W.H.; Huang, C.M.; Chou, S.C.T. An integrated cloud-based smart home management system with community hierarchy. IEEE Trans. Consum. Electron. 2016, 62, 1-9. [CrossRef]

46. Mokhtari, G.; Anvari-Moghaddam, A.; Zhang, Q. A New Layered Architecture for Future Big Data-Driven Smart Homes. IEEE Access 2019, 7, 19002-19012. [CrossRef]

47. Viswanath, S.K.; Yuen, C.; Tushar, W.; Li, W.T.; Wen, C.K.; Hu, K.; Chen, C.; Liu, X. System design of the internet of things for residential smart grid. IEEE Wirel. Commun. 2016, 23, 90-98. [CrossRef]

48. Bruno, S.; Dellino, G.; La Scala, M.; Meloni, C. A microforecasting module for energy management in residential and tertiary buildings. Energies 2019, 12, 1006. [CrossRef]

49. Sivapragash, C.; Padmanaban, S.; Eklas, H.; Holm-Nielsen, J.B.; Hemalatha, R. Location-based optimized service selection for data management with cloud computing in smart grids. Energies 2019, 12, 4517. [CrossRef]

50. Chen, Y.-Y.; Lin, Y.-H.; Kung, C.-C.; Chung, M.-H.; Yen, I.-H. Design and implementation of cloud analytics-assisted smart power meters considering advanced artificial intelligence as edge analytics in demand-side management for smart homes. Sensors 2019, 19, 2047. [CrossRef] [PubMed]

51. Aldossary, M.; Djemame, K.; Alzamil, I.; Kostopoulos, A.; Dimakis, A.; Agiatzidou, E. Energy-aware cost prediction and pricing of virtual machines in cloud computing environments. Future Gener. Comput. Syst. 2019, 93, 442-459. [CrossRef]

52. Bitzer, B.; Gebretsadik, E.S. Cloud computing framework for smart grid applications. In Proceedings of the Universities Power Engineering Conference, Dublin, Ireland, 2-5 September 2013.

53. Lin, Y.-H. Novel smart home system architecture facilitated with distributed and embedded flexible edge analytics in demand-side management. Int. Trans. Electr. Energy Syst. 2019, 29, e12014. [CrossRef]

54. Belli, G.; Giordano, A.; Mastroianni, C.; Menniti, D.; Pinnarelli, A.; Scarcello, L.; Sorrentino, N.; Stillo, M. A unified model for the optimal management of electrical and thermal equipment of a prosumer in a DR environment. IEEE Trans. Smart Grid 2019, 10, 1791-1800. [CrossRef]

55. Villegas-Ch, W.; Molina-Enriquez, J.; Chicaiza-Tamayo, C.; Ortiz-Garcés, I.; Luján-Mora, S. Application of a big data framework for data monitoring on a smart campus. Sustainability 2019, 11, 5552. [CrossRef]

56. Choi, J.S. A Hierarchical distributed energy management agent framework for smart homes, grids, and cities. IEEE Commun. Mag. 2019, 57, 113-119. [CrossRef]

57. Barros, E.B.C.; Filho, D.M.L.; Batista, B.G.; Kuehne, B.T.; Peixoto, M.L.M. Fog computing model to orchestrate the consumption and production of energy in microgrids. Sensors 2019, 19, 2642. [CrossRef] [PubMed]

58. Lilis, G.; Kayal, M. A secure and distributed message oriented middleware for smart building applications. Autom. Constr. 2018, 86, 163-175. [CrossRef]

59. Ferrández-Pastor, F.-J.; Mora, H.; Jimeno-Morenilla, A.; Volckaert, B. Deployment of IoT edge and fog computing technologies to develop smart building services. Sustainability 2018, 10, 3832. [CrossRef]

60. Bukhsh, R.; Javaid, N.; Ali Khan, Z.; Ishmanov, F.; Afzal, M.K.; Wadud, Z. Towards fast response, reduced processing and balanced load in fog-based data-driven smart grid. Energies 2018, 11, 3345. [CrossRef] 
61. Choi, S.; Min, S.W. Optimal Scheduling and Operation of the ESS for Prosumer Market Environment in Grid-Connected Industrial Complex. Proc. IEEE Trans. Ind. Appl. 2018, 54, 1949-1957. [CrossRef]

62. Ke, M.-T.; Yeh, C.-H.; Su, C.-J. Cloud computing platform for real-time measurement and verification of energy performance. Appl. Energy 2017, 188, 497-507. [CrossRef]

63. Munshi, A.A.; Mohamed, Y.A.-R.I. Big data framework for analytics in smart grids. Electr. Power Syst. Res. 2017, 151, 369-380. [CrossRef]

64. Kumar, N.; Singh, M.; Zeadally, S.; Rodrigues, J.J.P.C.; Rho, S. Cloud-assisted context-aware vehicular cyber-physical system for PHEVs in smart grid. IEEE Syst. J. 2017, 11, 140-151. [CrossRef]

65. Kumar, N.; Zeadally, S.; Misra, S.C. Mobile cloud networking for efficient energy management in smart grid cyber-physical systems. IEEE Wirel. Commun. 2016, 23, 100-108. [CrossRef]

66. Zhang, K.; Mao, Y.; Leng, S.; Maharjan, S.; Zhang, Y.; Vinel, A.; Jonsson, M. Incentive-Driven Energy Trading in the Smart Grid. IEEE Access 2016, 4, 1243-1257. [CrossRef]

67. Mohammadian, H.D. IoE-A solution for energy management challenges. In Proceedings of the IEEE Global Engineering Education Conference, EDUCON, Dubai, United Arab Emirates, 8-11 April 2019; IEEE Computer Society: Washington, DC, USA, 2019; pp. 1455-1461.

68. Ashraf, M.H.; Javaid, N.; Abbasi, S.H.; Rehman, M.; Sharif, M.U.; Saeed, F. Smart Grid Management Using Cloud and Fog Computing. In International Conference on Network-Based Information Systems; Springer: Cham, Switzerland, 2019; pp. 624-636.

69. KaleemUllah Khan, M.; Javaid, N.; Murtaza, S.; Zahid, M.; Ali Gilani, W.; Junaid Ali, M. Efficient Energy Management Using Fog Computing. In; 2019; pp. 286-299. In International Conference on Network-Based Information Systems; Springer: Cham, Switzerland, 2019; pp. 286-299.

70. Zambetti, M.; Cimini, C.; Pirola, F.; Pinto, R. Exploiting data analytics for improved energy management decision-making. In Proceedings of the Summer School Francesco Turco; AIDI-Italian Association of Industrial Operations: Senigallia, Italy, 2019; pp. 215-221.

71. Chou, J.-S.; Ngo, N.-T. Intelligent Monitoring for Efficient Use of Energy in Buildings. In Proceedings of the 2019 3rd International Conference on Smart Grid and Smart Cities, ICSGSC 2019, Berkeley, CA, USA, 25-28 June 2019; pp. 114-119.

72. Ashouri, M.; Davidsson, P.; Spalazzese, R. Cloud, edge, or both? Towards decision support for designing IoT applications. In Proceedings of the 2018 5th International Conference on Internet of Things: Systems, Management and Security, IoTSMS 2018, Valencia, Spain, 15-18 October 2018; Institute of Electrical and Electronics Engineers Inc.: Piscataway, NJ, USA, 2018; pp. 155-162.

73. Tseng, S.; Li, J.; Lee, M.; Wang, B.; Ji, F.; Bai, B. A software defined energy storage: Architecture, topology, and reliability. In Proceedings of the CIEEC 2017-Proceedings of 2017 China International Electrical and Energy Conference, Beijing, China, 25-27 October 2017; Institute of Electrical and Electronics Engineers Inc.: Piscataway, NJ, USA, 2017; pp. 737-741.

74. Pramudhita, A.N.; Asmara, R.A.; Siradjuddin, I.; Rohadi, E. Internet of Things Integration in Smart Grid. In Proceedings of the 2018 International Conference on Applied Science and Technology, iCAST 2018, Manado, Indonesia, 26-27 October 2018; pp. 718-722.

75. Medojevic, M.; Díaz Villar, P.; Cosic, I.; Rikalovic, A.; Sremcev, N.; Lazarevic, M. Energy management in industry 4.0 ecosystem: A review on possibilities and concerns. In Proceedings of the Annals of DAAAM and Proceedings of the International DAAAM Symposium, Zadar, Croatia, 24-27 October 2018; pp. 0674-0680.

76. Su, Z.; Xu, L.; Xin, S.; Li, W.; Shi, Z.; Guo, Q. A future outlook for cyber-physical power system. In Proceedings of the 2017 IEEE Conference on Energy Internet and Energy System Integration, EI2 2017-Proceedings, Beijing, China, 26-28 November 2017; Institute of Electrical and Electronics Engineers Inc.: Piscataway, NJ, USA, 2017; pp. 1-4.

77. Nefedov, E.; Vyatkin, V. Evaluating benefits of collaborative intelligent batteries in SmartGrid. In Proceedings of the IECON 2016-42nd Annual Conference of the IEEE Industrial Electronics Society, Florence, Italy, 23-26 October 2016; pp. 5265-5270.

78. Gupta, R.; Moinuddin; Kumar, P. Cloud computing data mining to SCADA for energy management. In Proceedings of the 12th IEEE International Conference Electronics, Energy, Environment, Communication, Computer, Control: (E3-C3), INDICON 2015, New Delhi, India, 17-20 December 2015.

79. Orgerie, A.-C. Interconnecting Smart Grids and Clouds to save Energy. In Proceedings of the 2015 International Conference on Smart Cities and Green ICT Systems (SMARTGREENS), Lisbon, Portugal, 20-22 May 2015. 
80. Bitzer, B.; Gebretsadik, E.S. Ensuring future clean electrical energy supply through cloud computing. In Proceedings of the 5th International Conference on Clean Electrical Power: Renewable Energy Resources Impact, ICCEP 2015, Taormina, Italy, 16-18 June 2015; Institute of Electrical and Electronics Engineers Inc.: Piscataway, NJ, USA, 2015; pp. 155-159.

81. Monti, A.; Ponci, F.; Ferdowsi, M.; McKeever, P.; Löwen, A. Towards a new approach for electrical grid management: The role of the cloud. In Proceedings of the 2015 IEEE International Workshop on Measurements and Networking, M and N 2015-Proceedings, Coimbra, Portugal, 12-13 October 2015; pp. 13-18.

82. Suciu, G.; Fratu, O.; Necula, L.; Pasat, A.; Suciu, V. Machine-to-Machine communications for Cloud-based energy management systems within SMEs. In Proceedings of the 2016 IEEE 22nd International Symposium for Design and Technology in Electronic Packaging, SIITME 2016, Oradea, Romania, 20-23 October 2016; Institute of Electrical and Electronics Engineers Inc.: Piscataway, NJ, USA, 2016; pp. 114-117.

83. Tahmasebi, M.; Khayyambashi, M.R. An efficient model for vehicular cloud computing with prioritizing computing resources. Peer-to-Peer Netw. Appl. 2019, 12, 1466-1475. [CrossRef]

84. Suciu, G.; Necula, L.; Iosu, R.; Usurelu, T.; Ceaparu, M. IoT and Cloud-Based Energy Monitoring and Simulation Platform. In Proceedings of the 2019 11th International Symposium on Advanced Topics in Electrical Engineering, ATEE 2019, Bucharest, Romania, 28-30 March 2019; Institute of Electrical and Electronics Engineers Inc.: Piscataway, NJ, USA.

85. Arias Barragán, L.A.; Rivas Trujillo, E.; Santamaria, F. Agente Integrador de Recursos Energéticos Distribuidos como Oferente de Energía en el Nivel de Distribución. Ingeniería 2017, 22, 306. [CrossRef]

86. Byun, J.; Hong, I.; Park, S. Intelligent cloud home energy management system using household appliance priority based scheduling based on prediction of renewable energy capability. IEEE Trans. Consum. Electron. 2012, 58, 1194-1201. [CrossRef]

87. Liu, C.; Li, N.; Li, L.; Liu, Y.; Zhao, Y.; Zhang, P.; Liang, L. Design and implementation of power dispatching management system based on cloud platform. In Proceedings of the 2nd International Conference on Big Data Research, Weihai, China, 27-29 October 2018; pp. 201-205.

88. Bitzer, B.; Gebretsadik, E.S. Cloud computing for monitoring and controlling of distributed energy generations. In Proceedings of the Universities Power Engineering Conference, Cluj-Napoca, Romania, 2-5 September 2014; IEEE Computer Society: Washington, DC, USA.

89. Lee, J.; Shin, Y.; Lee, I. Cloud-based application platform for smart monitoring \& management of photovoltaic generation systems. In Proceedings of the International Conference on Electronics, Information and Communication, ICEIC, Honolulu, HI, USA, 24-27 January 2018; Institute of Electrical and Electronics Engineers Inc.: Piscataway, NJ, USA, 2018; pp. 1-3.

90. Abid, A.J. Internet of energy: A design to manage energy consumption for off-grid building. Int. J. Autom. Smart Technol. 2019, 9, 13-22. [CrossRef]

91. Priyadharshini, S.G.; Subramani, C.; Preetha Roselyn, J. An IOT based smart metering development for energy management system. Int. J. Electr. Comput. Eng. 2019, 9, 3041-3050. [CrossRef]

92. Camarinha-Matos, L.M.; Oliveira, A.I.; Ferrada, F.; Thamburaj, V. Collaborative services provision for solar power plants. Ind. Manag. Data Syst. 2017, 117, 946-966. [CrossRef]

93. Makhsoos, A.; Mousazadeh, H.; Mohtasebi, S.S.; Abdollahzadeh, M.; Jafarbiglu, H.; Omrani, E.; Salmani, Y.; Kiapey, A. Design, simulation and experimental evaluation of energy system for an unmanned surface vehicle. Energy 2018, 148, 362-372. [CrossRef]

94. Martinez, C.M.; Hu, X.; Cao, D.; Velenis, E.; Gao, B.; Wellers, M. Energy Management in Plug-in Hybrid Electric Vehicles: Recent Progress and a Connected Vehicles Perspective. IEEE Trans. Veh. Technol. 2017, 66, 4534-4549. [CrossRef]

95. Khayyam, H.; Abawajy, J.; Javadi, B.; Goscinski, A.; Stojcevski, A.; Bab-Hadiashar, A. Intelligent battery energy management and control for vehicle-to-grid via cloud computing network. Appl. Energy 2013, 111, 971-981. [CrossRef]

96. Yao, J.; Zhang, Y.; Yan, Z.; Li, L. A group approach of smart hybrid poles with renewable energy, street lighting and EV charging based on DC micro-grid. Energies 2018, 11, 3445. [CrossRef]

97. Wan, C.; Zhao, J.; Song, Y.; Xu, Z.; Lin, J.; Hu, Z. Photovoltaic and solar power forecasting for smart grid energy management. CSEE J. Power Energy Syst. 2016, 1, 38-46. [CrossRef]

98. Bukhsh, R.; Javaid, N.; Javaid, S.; Ilahi, M.; Fatima, I. Efficient resource allocation for consumers' power requests in cloud-fog-based system. Int. J. Web Grid Serv. 2019, 15, 159-190. [CrossRef] 
99. Zheng, Y.; Chen, G. Energy Analysis and Application of Data Mining Algorithms for Internet of Things Based on Hadoop Cloud Platform. IEEE Access 2019, 7, 183195-183206. [CrossRef]

100. Yassine, A.; Hossain, M.S.; Muhammad, G.; Guizani, M. Double Auction Mechanisms For Dynamic Autonomous Electric Vehicles Energy Trading. IEEE Trans. Veh. Technol. 2019, 68, 7466-7476. [CrossRef]

101. Sayed, S.; Hussain, T.; Gastli, A.; Benammar, M. Design and realization of an open-source and modular smart meter. Energy Sci. Eng. 2019, 7, 1405-1422. [CrossRef]

102. Gómez-Romero, J.; Molina-Solana, M.; Ros, M.; Ruiz, M.D.; Martin-Bautista, M.J. Comfort as a service: A new paradigm for residential environmental quality control. Sustainability 2018, 10, 3053. [CrossRef]

103. Riekstin, A.C.; Rodrigues, B.B.; Nguyen, K.K.; De Brito Carvalho, T.C.M.; Meirosu, C.; Stiller, B.; Cheriet, M. A Survey on Metrics and Measurement Tools for Sustainable Distributed Cloud Networks. IEEE Commun. Surv. Tutor. 2018, 20, 1244-1270. [CrossRef]

104. You, X.; Li, Y.; Zheng, M.; Zhu, C.; Yu, L. A survey and taxonomy of energy efficiency relevant surveys in cloud-related environments. IEEE Access 2017, 5, 14066-14078. [CrossRef]

105. Kaur, T.; Chana, I. Energy efficiency techniques in cloud computing: A survey and taxonomy. ACM Comput. Surv. 2015, 48, 1-46. [CrossRef]

106. Giacobbe, M.; Celesti, A.; Fazio, M.; Villari, M.; Puliafito, A. Towards energy management in Cloud federation: A survey in the perspective of future sustainable and cost-saving strategies. Comput. Netw. 2015, 91, 438-452. [CrossRef]

107. Javied, T.; Bakakeu, J.; Gessinger, D.; Franke, J. Strategic energy management in industry 4.0 environment. In Proceedings of the 12th Annual IEEE International Systems Conference, SysCon 2018-Proceedings, Vancouver, BC, Canada, 23-26 April 2018; Institute of Electrical and Electronics Engineers Inc.: Piscataway, NJ, USA, 2018; pp. 1-4.

108. Sheikhi, A.; Rayati, M.; Bahrami, S.; Ranjbar, A.M.; Sattari, S. A cloud computing framework on demand side management game in smart energy hubs. Int. J. Electr. Power Energy Syst. 2015, 64, 1007-1016. [CrossRef]

109. Oprea, S.-V.; Pîrjan, A.; Cărutasu, G.; Petrosanu, D.-M.; Bâra, A.; Stănică, J.-L.; Coculescu, C. Developing a mixed neural network approach to forecast the residential electricity consumption based on sensor recorded data. Sensors (Switzerland) 2018, 18, 1443. [CrossRef]

110. Capizzi, G.; Lo Sciuto, G.; Napoli, C.; Tramontana, E. Advanced and adaptive dispatch for smart grids by means of predictive models. IEEE Trans. Smart Grid 2018, 9, 6684-6691. [CrossRef]

111. Talei, H.; Essaaidi, M.; Benhaddou, D. Smart campus energy management system: Advantages, architectures, and the impact of using cloud computing. In Proceedings of the 2017 International Conference on Smart Digital Environment, Rabat, Morocco, 21-23 July 2017; pp. 1-7.

112. Siddiqa, A.; Hashem, I.A.T.; Yaqoob, I.; Marjani, M.; Shamshirband, S.; Gani, A.; Nasaruddin, F. A survey of big data management: Taxonomy and state-of-the-art. J. Netw. Comput. Appl. 2016, 71, 151-166. [CrossRef]

113. Agavanakis, K.; Papageorgas, P.G.; Vokas, G.A.; Ampatis, D.; Salame, C. Energy trading market evolution to the energy internet a feasibility review on the enabling internet of things (IoT) cloud technologies. In Proceedings of the AIP Conference Proceedings, Beirut, Lebanon, 1-3 February 2018; AIP Publising LLC: Melville, NY, USA, 2018; Volume 1968.

114. Belli, G.; Brusco, G.; Burgio, A.; Motta, M.; Menniti, D.; Pinnarelli, A.; Sorrentino, N. An energy management model for energetic communities of Smart Homes: The Power Cloud. In Proceedings of the 2017 IEEE 14th International Conference on Networking, Sensing and Control, ICNSC 2017, Calabria, Italy, 16-18 May 2017; Institute of Electrical and Electronics Engineers Inc.: Piscataway, NJ, USA, 2017; pp. 158-162.

115. Barcelo, M.; Correa, A.; Llorca, J.; Tulino, A.M.; Vicario, J.L.; Morell, A. IoT-Cloud Service Optimization in Next Generation Smart Environments. IEEE J. Sel. Areas Commun. 2016, 34, 4077-4090. [CrossRef]

116. Pietras-Szewczyk, M. Appraisement of geographic information systems as tool supporting energy management in the cities. Energy Environ. 2017, 28, 437-450. [CrossRef]

117. Xin, S.; Guo, Q.; Wang, J.; Chen, C.; Sun, H.; Zhang, B. Information masking theory for data protection in future cloud-based energy management. IEEE Trans. Smart Grid 2018, 9, 5664-5676. [CrossRef]

118. Liu, Z.; Yang, J.; Song, W.Z.; Xue, N.; Li, S.; Fang, M. Research on cloud energy storage service in residential microgrids. IET Renew. Power Gener. 2019, 13, 3097-3105. [CrossRef]

119. Chen, Y.-W.; Chang, J.M. Fair Demand Response With Electric Vehicles for the Cloud Based Energy Management Service. IEEE Trans. Smart Grid 2016, 9, 458-468. [CrossRef] 
120. Naveen, P.; Ing, W.K.; Danquah, M.K.; Sidhu, A.S.; Abu-Siada, A. Cloud computing for energy management in smart grid - An application survey. In Proceedings of the IOP Conference Series: Materials Science and Engineering, Miri, Malaysia, 6-8 November 2015; Volume 121.

121. Atat, R.; Liu, L.; Wu, J.; Li, G.; Ye, C.; Yang, Y. Big Data Meet Cyber-Physical Systems: A Panoramic Survey. IEEE Access 2018, 6, 73603-73636. [CrossRef]

122. Manur, A.; Venkataramanan, G.; Sehloff, D. Simple electric utility platform: A hardware/software solution for operating emergent microgrids. Appl. Energy 2018, 210, 748-763. [CrossRef]

123. Kalaivani, K.; Venugopal, N. A secured smart frame for bigdata information management in cloud. Int. J. Control Theory Appl. 2016, 9, 6143-6149.

124. Diamantoulakis, P.D.; Kapinas, V.M.; Karagiannidis, G.K. Big Data Analytics for Dynamic Energy Management in Smart Grids. Big Data Res. 2015, 2, 94-101. [CrossRef]

125. Baktir, S. Privacy preserving smart grid management in the cloud. In Proceedings of the 2014 International Conference on IT Convergence and Security, ICITCS 2014, Beijing, China, 28-30 October 2014.

126. Choi, C.; Esposito, C.; Wang, H.; Liu, Z.; Choi, J. Intelligent power equipment management based on distributed context-aware inference in smart cities. IEEE Commun. Mag. 2018, 56, 212-217. [CrossRef]

127. Yaghmaee, M.H.; Leon-Garcia, A.; Moghaddassian, M. On the Performance of Distributed and Cloud-Based Demand Response in Smart Grid. IEEE Trans. Smart Grid 2018, 9, 5403-5417. [CrossRef]

128. Perrons, R.K. How the energy sector could get it wrong with cloud computing. Energy Explor. Exploit. 2015, 33, 217-226. [CrossRef]

(C) 2020 by the authors. Licensee MDPI, Basel, Switzerland. This article is an open access article distributed under the terms and conditions of the Creative Commons Attribution (CC BY) license (http://creativecommons.org/licenses/by/4.0/). 